\title{
Diversity, Equity, and Inclusion: Language, Concepts, and Intent Mapped Through History
}

\author{
Adrienne R. Minerick, Michigan Technological University \\ Milo D. Koretsky, Tufts University
}

$\mathrm{R}$ ecently Chemical Engineering Education (CEE) has been improving readers' access to its digital archival records. During this process, the role of this archival journal in documenting the chemical engineering community's past engagement in social injustice and racial advocacy surfaced. In particular, a conversation emerged around shifting norms in language, concepts, and advocacy used to engage individuals from underserved backgrounds. In this editorial we outline some of the ideas that emerged as part of this exchange, not with the intent that a given historical perspective is "right," but rather that understanding historical rhetoric, attitudes, and practices enables us to learn from and extend conversations and actions within our community. We write from the lived experiences of two White academics, one cisgender, heterosexual woman in her $40 \mathrm{~s}$ and one cisgender, heterosexual Jewish man in his 50s, who actively engage in advocacy.

CEE was established in the 1960s as the archival journal serving chemical engineering educators. The period was a time of racial unrest and turmoil in response to structural discrimination restricting access to schools, housing, and jobs - as manifest by the Watts rebellion in 1965, and followed by widespread urban unrest in the summers of 1967 (in Detroit, Newark, Saginaw, Cincinnati, ...) and 1968 (in Washington DC, Chicago, Kansas City, New York, Trenton, ...). As has been eloquently detailed in recent books ${ }^{[1]}$ and movies, ${ }^{[2]}$ legacy attitudes and frameworks from this period are reflected in the widespread protests in 2020 and 2021 in response to ongoing systemic racism and the murders of George Floyd, Breonna Taylor, and others. Similar to the engineering education community's current focus on anti-racist pedagogy, ${ }^{[3-5]}$ in the 1960s CEE published articles and editorials in which educators sought to leverage compassion and educate on race in situations, attitudes, and programs. Some of the language used, while generally accepted in the 1960s, is not appropriate today; however, the concepts and advocacy embraced at the time offer valuable lessons from which to learn. So, in the archiving process, we faced the conundrum of how to remain faithful to the historical record while, simultaneously, being sensitive to language or outdated approaches and how that might impact current readers from different social groups and identity affiliations.
This context led to discussion of the following ideas surrounding language, concepts, and intent:

Language matters. And language is situated in time and space. Terms sit within a historical context, and it is useful to understand that context in making sense of the words that were employed to convey concepts and activities ${ }^{[6,7]}$ Thus, in an archival evaluation, it is appropriate to ask, "Is it the language that the subaltern group preferred at the time?" As such, it is productive to recognize the vector of history. For example, one of the racial identifiers used in CEE in the 1960s, "Negro," is unpalatable today. However, it was widely used in the 1960s, including by leaders of the Black community such as Martin Luther King Jr., Supreme Court Justice Thurgood Marshall, and novelist and racial critic James Baldwin. When the sociologist W.E.B. Du Bois suggested the term "Negro" improved upon the category "Colored," he did so within the social and cultural norms of the 1920s. Later, these norms shifted in the 1960s and led civil rights activist Stokely Carmichael to choose to reject the term "Negro." In part, the shifting language is in response to the ways that the socially constructed categories of race have been used to legitimize American and European domination within the historical context of imperialism and colonialism. Due to these shifting norms of language, $C E E$ no longer uses "Negro" and other terms denoting race that are now considered outdated. $C E E$ 's full archive, including the papers from the 1960s, will continue to be available digitally as part of the journal's historical record. The journal will include a statement of historical context at the beginning of any materials that contain language now considered inappropriate, including a date as to when that determination was made. $C E E$ staff and reviewers will remain attentive to current discussions about language and race, making updates to style standards when appropriate.

Concepts matter. And concepts are situated in time and space. As we read the archival articles from the 1960s, the concepts discussed and the efforts and programs described were framed from a desire to react in productive ways to the racial unrest and growing awareness of differing access. However, strategies were predominantly framed in the form of a great White savior bestowing education and resources upon the downtrodden. ${ }^{[8]}$ Notions 
of the need for a White savior build on historical misconceptions of Black people as a pathological race that had its own innate (by nature) demise built into them. ${ }^{\left[{ }^{[9}\right.}$ Since then, we have iteratively learned that individuals from systemically underserved backgrounds achieve greater success with access, authorship, and authority. ${ }^{[10]}$ Efforts and programs better serve communities when the focal community member voices become central in ideation, concept development, and program implementation. Self-authorship is an important concept to incorporate in diversity, equity, and inclusivity efforts. ${ }^{[11,12]}$ Involving impacted communities in the conversation and listening carefully are critical because the system, concepts, and motivations that are appealing to the majority may not simultaneously be appealing or the same for each unique underserved group. These conversations can reveal latent biases and barriers within systems and practices perceived to be neutral. ${ }^{[13]}$ Thus, our concept of countering impacts from systemic underserving of certain races of individuals has shifted from the savior framing of the 1960 s to an advocate framework in the 2020s. Undoubtedly, our concepts will continue to develop. The future state of affairs will certainly be better if we listen, learn, and empower everyone to understand and embrace a trajectory that incorporates lessons from the concepts and actions of the past and present.

Intent matters, but so does impact. And intent persists through time and space. Good intentions are a necessary raw material for progress in diversity, equity, and inclusion efforts. Yet, there is a limit to good intentions - the catalyst of language within the structure of concepts is essential, even as language and concepts shift in time and space, to ultimately produce positive impact. In other words, beneficial impact is more likely realized when good intent, appropriate language, and well-informed concepts align with respectful social interactions. Language and concepts can be learned through community participation and engagement. In the steady march to inclusion and equity, we believe judicious educational side conversations often lead to better longer-term outcomes. ${ }^{[14]}$ For some people with good intentions, fear of utilizing the right terminology can result in limited engagement in and avoidance of critical issues and systemic barriers. Such avoidance only perpetuates the unjust disadvantages of those historically excluded or disadvantaged. Thus, when we reflect on past contributions, such as we did during the archival process of $C E E$, we can recognize and acknowledge the underlying intent of allyship - even if language and concepts are inconsistent with our current frame. In that vein, those early contributors to $C E E$ displayed necessary courage and independent thinking, challenging societal norms (during that time and space) to be allies and positively contribute in the long path towards equity within the chemical engineering education community.

We strongly support Chemical Engineering Education's recent editorial initiative that submissions must address "diversity, equity, and inclusion issues within the body of the work, as a separate sub-section of the work or within a letter of submission. (Required for all submissions starting 1/1/21)." As the authors in our community grapple with these issues, we encourage them to become avid students of the shifting uses of language and concepts in this arena while, at the same time, valuing the positive intent of those from very different lived experiences.

\section{ACKNOWLEDGMENTS}

The authors gratefully acknowledge Eileen Otis, Dwaine Plaza, Ashlee Ford Versypt, Tayloria Adams, and Norman Fortenberry for useful feedback on early drafts of this editorial.

\section{REFERENCES}

1. Alexander M (2012) The New Jim Crow: Mass Incarceration in the Age of Colorblindness. New Press. New York, NY.

2. 13th. https://www.netflix.com/title/80091741.

3. Long LL III (2020) Toward an antiracist engineering classroom for 2020 and beyond: A starter kit. J. Eng. Educ. 109(4): 636639. DOI: https://doi.org/10.1002/jee.20363

4. Black in Engineering (2020) On becoming an anti-racist university. https://blackinengineering.org/action-item-list/.

5. Bodnar C and Felse A (2018) Introduction to Special Section on Diversity. Chem. Eng. Ed. 52(2):70-71.

6. Bruner J (1986) Actual Minds, Possible Words. Harvard University Press. Cambridge, MA.

7. Spivak GC (1988) Can the subaltern speak? Nelson C and Grossberg L (Eds) Marxism and the Interpretation of Culture. University of Illinois Press. Champaign, IL. 271-313.

8. Aronson BA(2017) The white savior industrial complex: A cultural studies analysis of a teacher educator, savior film, and future teachers. Journal of Critical Thought and Praxis. 6(3): 36-54.

9. Muhammad KG (2019) The Condemnation of Blackness: Race, Crime, and the Making of Modern Urban America. Harvard University Press. Cambridge, MA.

10. Johnson A, Brown J, Carlone H, and Cuevas AK (2011) Authoring identity amidst the treacherous terrain of science: A multiracial feminist examination of the journeys of three women of color in science. J. Res. Sci. Teach. 48(4): 339-366.

11. Johnston-Guerrero MP (2017) Reasoning through race: College students of color and the dynamics of racial authority. J. Divers. High. Educ. 10(1): 72-85.

12. Magolda MB (2008) Three elements of self-authorship. J. Coll. Stud. Dev. 49(4): 269-84.

13. Desai TA., Eniola-Adefeso O, Stevens KR et al. (2021) Perspectives on disparities in scientific visibility. Nat. Rev. Mater. 6: 556-559. https://doi.org/10.1038/s41578-021-00329-5

14. Bennett $\mathrm{J}$ (2021) What if instead of calling people out, we called them in? Prof. Loretta J. Ross is combating cancel culture with a popular class at Smith College. NY Times, Feb. 24, $2021 \square$ 